Atsushi Ogawa $\cdot$ Shigenori Yamamoto $\cdot$ Masaki Takayanagi

Toshiaki Kogo $\cdot$ Masaki Kanazawa $\cdot$ Yoichi Kohno

\title{
Identification of three novel mutations in the MNK gene in three unrelated Japanese patients with classical Menkes disease
}

\begin{abstract}
Menkes disease is an X-linked recessive disorder of the copper membrane transport system caused by mutations to the Menkes $(M N K)$ gene. We identified three novel mutations of the $M N K$ gene in three unrelated Japanese patients with classical Menkes disease by analyzing reversetranscriptase polymerase chain reaction products and genomic DNA of the $M N K$ gene. Firstly, an insertional mutation was found, 1173 ins $\mathrm{A}$, which led to a premature termination and resulted in a very immature Menkes protein. Secondly, we found a point mutation, T2763G, resulting in a leucine-to-arginine conversion, which we predicted would cause a change in the secondary structure of the Menkes protein. Finally, we identified a splicing mutation, $2317+5 \mathrm{G}>\mathrm{C}$, which resulted in the skipping of both exons 8 and 9 or exon 9 only, and led to a truncation of the protein. Each of these mutations is hypothesized to destroy copperATPase-mediated copper transport. We propose that each of these mutations in the $M N K$ gene plays a causative role in the disease.
\end{abstract}

Key words Menkes disease $\cdot M N K$ gene $\cdot$ ATP7A $\cdot$ mutation $\cdot$ Japanese

\footnotetext{
A. Ogawa $(\bowtie) \cdot$ S. Yamamoto $\cdot$ T. Kogo $\cdot$ M. Kanazawa $\cdot$ Y. Kohno Department of Pediatrics, Chiba University School of Medicine, 1-8-1 Inohana, Chuo-ku, Chiba-shi, Chiba 260-8670, Japan

Tel. +81-43-226-2144; Fax +81-43-226-2145

e-mail: aogawa@pediat3.m.chiba-u.ac.jp

M. Takayanagi

Division of Metabolism, Chiba Children's Hospital, Chiba, Japan

T. Kogo $\cdot$ M. Kanazawa

Division of Pediatrics, National Sanatorium Shimoshizu Hospital,

Chiba, Japan
}

\section{Introduction}

Menkes disease is an X-linked recessive disorder of copper transport, characterized by neurodegeneration in infancy, failure to thrive, and abnormalities of the connective tissues (Menkes et al. 1962). Recently, the Menkes (MNK) gene has been isolated. The gene codes for a protein that is predicted to be a P-type cation-transporting ATPase (ATP7A) (Vulpe et al. 1993; Chelly et al. 1993; Mercer et al. 1993), based on an analysis of the gene products similarity with a bacterial form of copper-transporting ATPase, and the presence of a putative metal-binding motif at the Nterminus (Vulpe et al. 1993). Various authors (Das et al. 1994; Tümer et al. 1997) have found mutations in the $M N K$ gene obtained from patients with Menkes disease. The mutations exist in a wide variety of forms, including cytogenetic abnormalities (Tümer et al. 1992), partial deletions, and single-base-pair changes. At present, there have been no reports of mutations in the $M N K$ gene amongst the Japanese population. The purpose of this study was to explore the presence of mutations in the $M N K$ gene in three unrelated Japanese patients with classical Menkes disease.

\section{Subjects and methods}

Subjects

Table 1 summarizes the principal features of the three putative Menkes patients. The diagnosis of Menkes disease was made on the basis of the biochemical analysis of the accumulation of intracellular copper in cultured fibroblasts. Classification of the phenotype was based mainly on clinical symptoms. Cases 2 and 3 were severely affected and both had died by 3 years of age. Case 1 had severe symptoms but survived for more than 6 years. Because of this unusually extended survival time, this patient was classified as having an aclassical form of the disease (Horn et al. 1995). Informed consent for the study was obtained from the parents of each patient. 
Table 1 Summary of the characteristics of three Japanese patients with classical Menkes disease

\begin{tabular}{|c|c|c|c|}
\hline & Patient 1 & Patient 2 & Patient 3 \\
\hline Kinky hair & Yes & Yes & Yes \\
\hline Hypothermia in infancy & Yes & Yes & None \\
\hline Bladder diverticula & Yes & Yes & Yes \\
\hline Survival (years) & Died at age 9 years & Died at age 2 years & Died at age 3 years \\
\hline Serum Cu level $(\mu \mathrm{g} / \mathrm{dl})^{\mathrm{a}}$ & 23 & 1.0 & 17 \\
\hline Serum ceruloplasmin $(\mathrm{mg} / \mathrm{dl})^{\mathrm{b}}$ & 6.2 & 8.0 & 11 \\
\hline Copper in fibroblasts (ng $\mathrm{Cu} / \mathrm{mg}$ protein $)^{\mathrm{c}}$ & 174 & 259 & 199 \\
\hline Mutation & 1173 ins $\mathrm{A}$ & T2763G & $2317+5 \mathrm{G}>\mathrm{C}$ \\
\hline Consequence & Y343X & L873R & $\begin{array}{l}\text { skipping of exons } 8 \text { and } 9 \\
\text { or exon } 9 \text { only }\end{array}$ \\
\hline
\end{tabular}

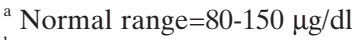

${ }^{\mathrm{b}}$ Normal range $=20-46 \mathrm{mg} / \mathrm{dl}$

${ }^{\mathrm{c}}$ Control males $(n=5), 19.8 \pm 12.1 \mathrm{ng} \mathrm{Cu} / \mathrm{mg}$ protein

Measurement of copper concentration in fibroblasts

Fibroblasts obtained from the Menkes patients $(n=3)$ and control subjects $(n=5)$ were incubated in RPMI 1640 medium supplemented with $10 \%$ fetal bovine serum. The copper concentration of this medium was approximately 10 $\mathrm{ng} \cdot \mathrm{ml}^{-1}$. Following three washes in an isotonic buffer solution, the harvested cells were suspended in deionized water and disrupted by sonication. The protein content was measured by the dye dilution method. The copper concentration was determined by atomic absorption spectrophotometry using a carbon-rodatomizer. The results are presented in $\mathrm{ng} \cdot \mathrm{mg}^{-1}$ protein.

\section{DNA sequencing}

Cultured skin fibroblasts were used for poly A+ RNA isolation. The 4.5-kb coding region (Vulpe et al. 1993) was divided into four overlapping segments and each segment was amplified by reverse-transcriptase polymerase chain reaction (RT-PCR). The number of nucleotides present in each of the segments was: segment $1 ; 106-1308$; segment 2 ; 1088-2450; segment 3; 2330-3608; and segment 4; 34384758.

Amplified segments were cloned into a pCR-Script SK(+) vector (Stratagene, La Jola, CA, USA) and sequenced using a DNA sequencer (DSQ 1000L; Shimazu, Kyoto, Japan) along with the fluorescent dye primers M4 and RV-M. Identified mutations were additionally confirmed by the sequencing of genomic DNA. Further confirmation of the gene mutations was achieved on the basis of restriction enzyme digestion analysis. None of the three mutations caused modification of the restriction sites in the $M N K$ gene. Additional base substitutions were therefore artificially introduced into the region of each mutation site. For the 1173 ins A mutation, an artificial SspI site (AATATI; the substitution in the primer sequence is underlined and 1173 ins $\mathrm{A}$ is shown in bold type) was introduced into the 1173 ins A sequence, but not into the wild-type sequence. For the T2763G mutation, an artificial SphI site (GCATGC; formating conventions as above;
T2763G is shown in bold type) was introduced into the T2763G sequence, but not into the wild-type sequence. For $2317+5 \mathrm{G}>\mathrm{C}$, an artificial ApaLI site (GTGCAC; formating conventions as above; $2317+5 \mathrm{G}$ is shown in bold type) was introduced into the wild-type sequence, but not into the $2317+5 \mathrm{G}>\mathrm{C}$ sequence. The PCR products were digested with an appropriate restriction enzyme and then electrophoresed.

\section{Results and Discussion}

We analyzed the $M N K$ gene in three unrelated Japanese patients with classical Menkes disease, and identified three novel mutations. Note that this is the first report of mutations of the $M N K$ gene in Japanese patients.

Table 1 shows the copper concentrations measured in fibroblasts that had been cultured from control subjects and the patients. The mean copper concentration in the control tissue was $19.8 \mathrm{ng} \cdot \mathrm{mg}^{-1}$ of protein. The copper concentrations in the tissues from the patient group were significantly higher (mean 210, SD 43.7) than the control values, which provided further confirmation of the diagnosis of Menkes disease in the patient group.

The mutations of the $M N K$ gene are summarized in Fig. 1. In case 1 , an insertional mutation, 1173 ins $\mathrm{A}$, was found (Fig.1a). The mutation lead to a premature termination at codon number 343 , resulting in a very immature Menkes protein. For example, the gene product from the insertional mutant contained only three metal-binding domains. In the genetic analysis of case 2, a T-to-G transversion at nucleotide position 2763 was found (Fig.1b), resulting in a leucine-to-arginine conversion at codon number 873 . This nucleotide change was not found in 100 alleles of X-chromosomes obtained from the normal Japanese control subjects, suggesting that the transversion does not represent a polymorphism in the gene. A prediction analysis, using the Chou-Fasman method, suggested that this T-to-G transversion would cause an amino acid substitution, which would be likely to modify the secondary structure of the mutant gene product. We hypothesize that this mutation, 
$\mathbf{a}$

control

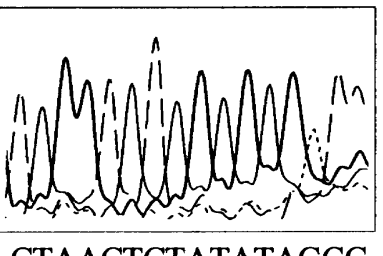

CTAACTCTATATAGCC

case 1

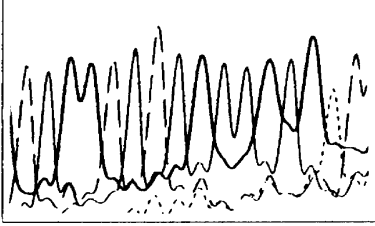

CTAACTCTATTATAGC

b

control

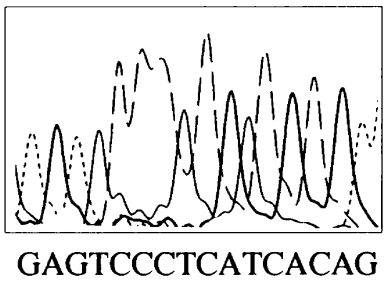

case 2

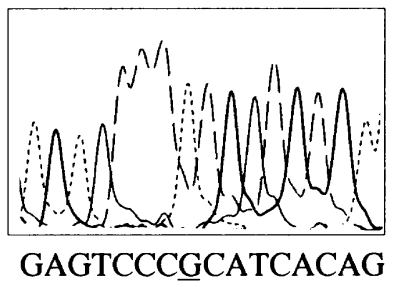

c

control

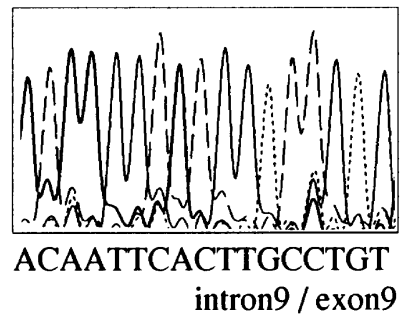

case 3

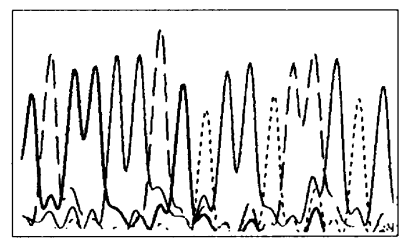

ACAATTCAGTTGCCTGT

intron9 / exon9

Fig. 1a-c. Sequencing results for the genomic DNA from each of the three patients and the controls. Underlined letters indicate the identified nucleotide change. The results presented for cases 1 and 3 show the antisense sequence, while the results for case 2 show the sense sequence. a 1173 ins A, b T2763G, c 2317+5G >C

located within the highly conserved phosphatase domain, could eliminate the phosphatase activity of the protein. In case 3, the RT-PCR amplified segment 2 (nucleotide position 1084-2450) yielded two products, which were smaller than would be expected from a sequence of comparable length (data not shown). Each fragment was cloned and sequenced. Exon 9 was skipped in the transcript derived from the first of the two fragments. In the transcript derived from the second fragment, exon 8 and exon 9 were skipped.

The sequencing of the genomic DNA revealed a G-to$\mathrm{C}$ transversion in a splice donor site adjacent to the $3^{\prime}$-end of exon 9 (Fig.1c). No nucleotide change was found in either the $5^{\prime}$-end or the $3^{\prime}$-end of the exon-intron junction of exon 8. The mutation in the splicing donor site of exon 9 resulted in a reduction in the splicing score from 0.82 to 0.68 . Our analysis indicates that the mutation in which exon 9 was skipped would lead to a shift in the reading frame. The predicted shift in the reading frame would cause a premature stop codon to be read in the sequence, which would, in turn, result in the production of an immature protein.

Analysis of the second transcript revealed that there was skipping of both exons 8 and 9. While our analysis suggested that this mutation would not cause a change in the reading frame, we would predict that such a mutation could still affect the capacity for the mutant gene-product to function as an ATPase-mediated copper-transport molecule. Exon 8 encodes the region of the ATP7A protein that lies between the final metal-binding domain and the first transmembrane domain. The specific function of this region is not well defined; however, it may play an important role in maintaining the secondary structure of all six of the metal-binding domains. Exon 9 encodes for the first and second transmembrane domains of the ATP7A protein. As described above, the splicing mutation, $2317+5 \mathrm{G}>\mathrm{C}$, would lead to a truncated gene product. We would also predict that this would affect the capacity of the resulting protein to function as a copper-transporting ATPase.

Using the results of the mutation analyses reported above, we performed a carrier diagnosis in the mothers of case 1 and case 3 . We extracted genomic DNA from leucocytes obtained from each mother and amplified the 
mutation-bearing exon, including the surrounding exon/ intron boundaries. The PCR fragments were subcloned into the pGEM-T vector (Promega, Madison, WI, USA) and sequenced in order to search for mutations. With regard to case 1, the insertional mutation 1173 ins $\mathrm{A}$ was found in four of eight of the clones. With regard to case 2, the splicing mutation $2317+5 \mathrm{G}>\mathrm{C}$ was found in five of eight of the clones. These results indicate that the mutations identified in case 1 and in case 3 were not de novo, but were, instead, inherited from the mother. A prenatal molecular-genetic diagnosis may therefore be possible in these families.

In this study, we identified three novel mutations in three unrelated Japanese patients with classical Menkes disease. Each of the mutations is hypothesized to destroy the capacity of the resulting gene products to function as a copper-transporting ATPase molecule. We therefore propose that each of these mutations of the $M N K$ gene, which we have identified from three unrelated Japanese Menkes patients, may be of direct relevance to the disease.

Acknowledgments We thank Professor Yasuhiro Kuroda at the Department of Pediatrics, Tokushima University School of Medicine, for providing the patient materials forming the basis of the analysis of patient 2.

\section{References}

Chelly J, Tümer Z, Tønnesen T, Petterson A, Ishikawa-Brush Y, Tommerup N, Horn N, Monaco AP (1993) Isolation of a candidate gene for Menkes disease that encodes a potential heavy metal binding protein. Nature Genet 3: 14-19

Das S, Levinson B, Whitney S, Vulpe C, Packman S, Gitschier J (1994) Diverse mutations in patients with Menkes disease often lead to exon skipping. Am J Hum Genet 55: 883-889

Horn N, Tønnesen T, Tümer Z (1995) Variability in clinical expression of an X-linked copper disturbance, Menkes disease. In: Sarkar B (ed) Genetic response to metals. Marcel Dekker, New York, pp 285-303

Menkes JH, Alter M, Steigleder GK, Weakley DR, Sung JH (1962) A sex-linked disorder with retardation of growth, peculiar hair and focal cerebral and cerebellar degeneration. Pediatrics 29: 764-779

Mercer JFB, Livingston J, Hall B, Paynter JA, Begy C, Chandrasekharappa S, Lockhart P, Grimes A, Bhave M, Siemieniak D, Glover TW (1993) Isolation of a partial candidate gene for Menkes disease by positional cloning. Nature Genet 3: 20-25

Tümer Z, Tommerup N, Tønnesen T, Kreuder J, Craig IW, Horn N (1992) Mapping of the Menkes locus to Xq13.3 distal to the Xinactivation center by an intrachromosomal insertion of the segment Xq13.3-q21.2. Hum Genet 88: 668-672

Tümer Z, Lund C, Tolshave J, Vural B, Tønnesen T, Horn N (1997) Identification of point mutations in 41 unrelated patients affected with Menkes disease. Am J Hum Genet 60: 63-71

Vulpe C, Levinson B, Whitney S, Packman S, Gitschier J (1993) Isolation of a candidate gene for Menkes disease and evidence that it encodes a copper-transporting ATPase. Nature Genet 3: 7-13 